\title{
AN ABNORMAL SPECIMEN OF BEMBIDIUM SCUDDERI.
}

\author{
BY ROLAND HAYWARD, MILTON, MASS.
}

While examining a number of examples of Bembidium scudderi recently received from Mr. H. F. Wickham from Humboldt Lake, Nev., I noticed a curious monstrosity in a specimen of that species which seems of sufficient interest to publish.

As is well known the dorsal punctures of the elytra are very constant both in number and position in our numerous species of Bembidium, and afford very useful characters for the subdivision of the genus into groups. With few exceptions they are two in number and are situated either on the third interval or the third stria. In two of our groups, one containing levigatum, and the other semistriatum and constricticolle, they are placed in irregular rows on all the intervals. In two others they are three in number, being situated on the third stria in that of which rickseckeri is the type, while in the group containing henshazi, consimile, scudderi and hageni they are on the third interval.

In the specimen before me there are on the third interval of the left elytron the abnormal number of four punctures, while on that of the right there are three, placed as in normal specimens. On the left elytron the first puncture is in normal position, the second, however, is situated much nearer the base, while between it and the one nearest the apex, which is situated as on the right elytron, is interpolated an additional puncture, placed nearly midway between the second and fourth, but slightly nearer the latter. A curious fact to be observed is that only the first, second and fourth punctures are setigerous, the third showing no trace of seta. The setæ arising from the three dorsal punctures of the right elytron are also distinct.

Of course the case is a monstrosity only, showing as it does, in a small way, a deviation from bilateral symmetry, but it seems interesting that it should occur in a member of a group in which the normal number of dorsal punctures is in excess of that occurring in the vast majority of our species, and may possibly indicate an inherited tendency toward an increase in their number.

The group as a whole is confined to the western portions of our country and to Mexico. Only one species, $B$. consimile, occurs as far east as Nebraska, extending westward to Utah, while henshurai $i$ and scudderi occur in the region between western $W$ yoming and California. All three are found, as I learn from correspondents, on alkaline mud along the shores of saline lakes and ponds. Of the haoits of hageni nothing is known. 

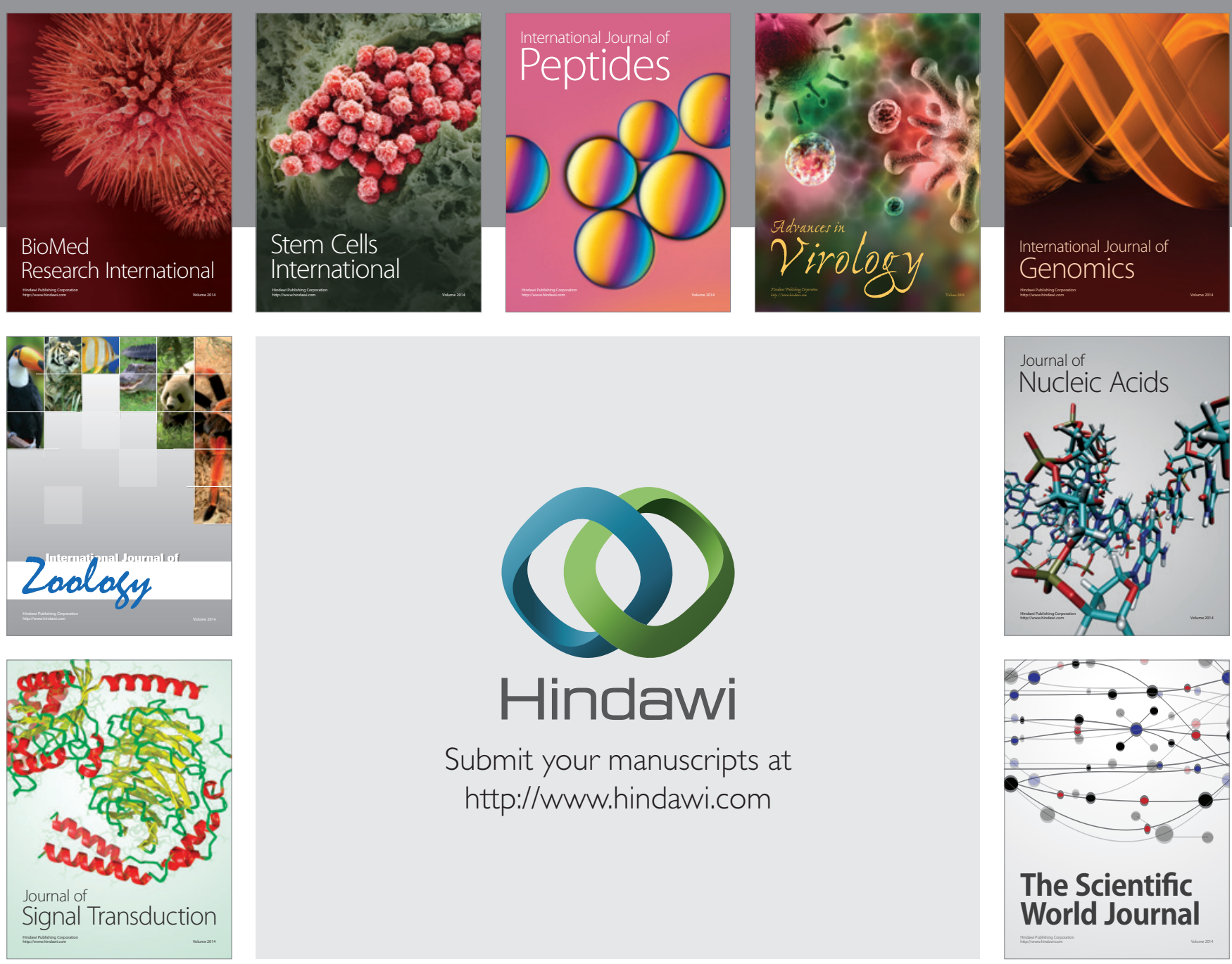

Submit your manuscripts at

http://www.hindawi.com
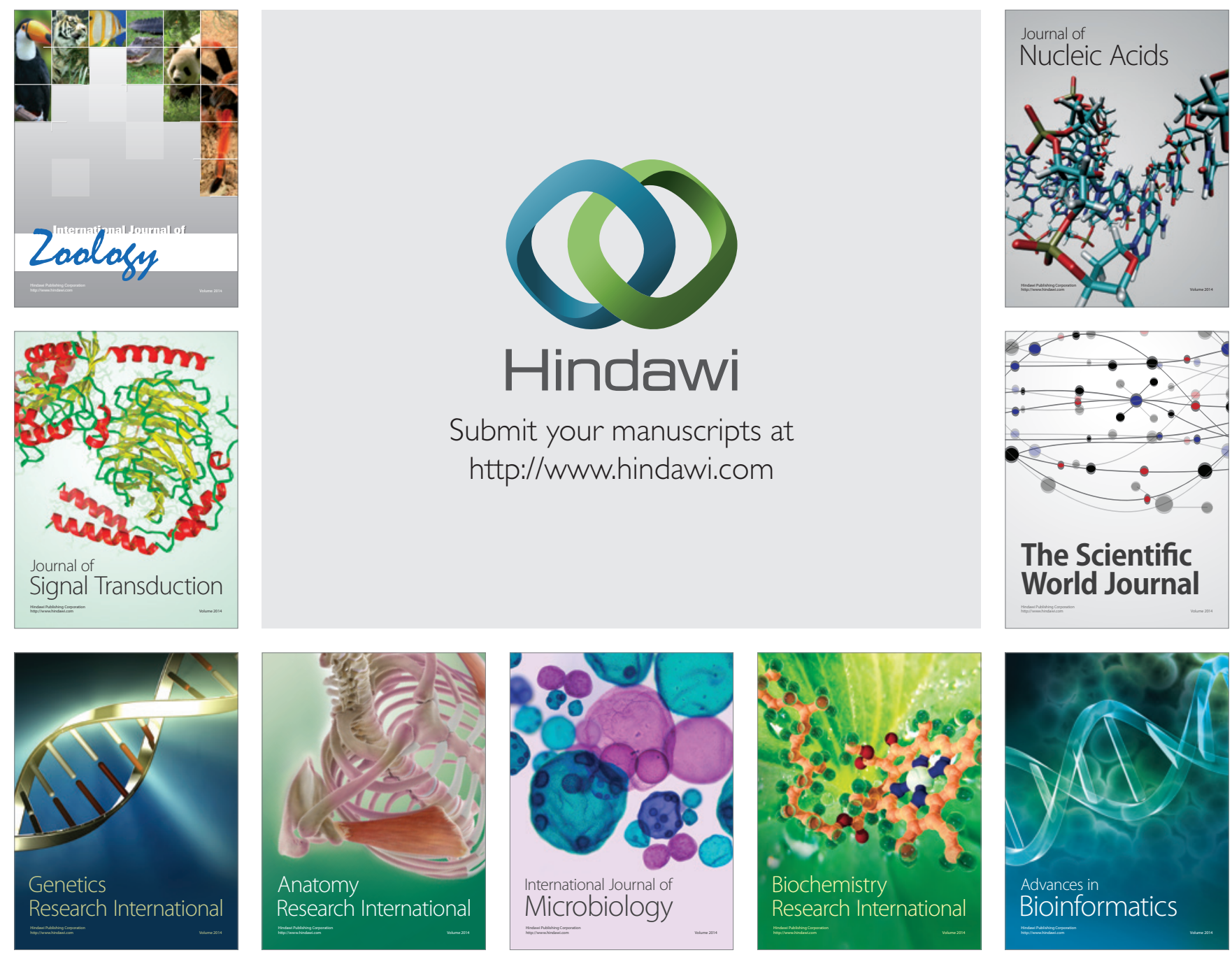

The Scientific World Journal
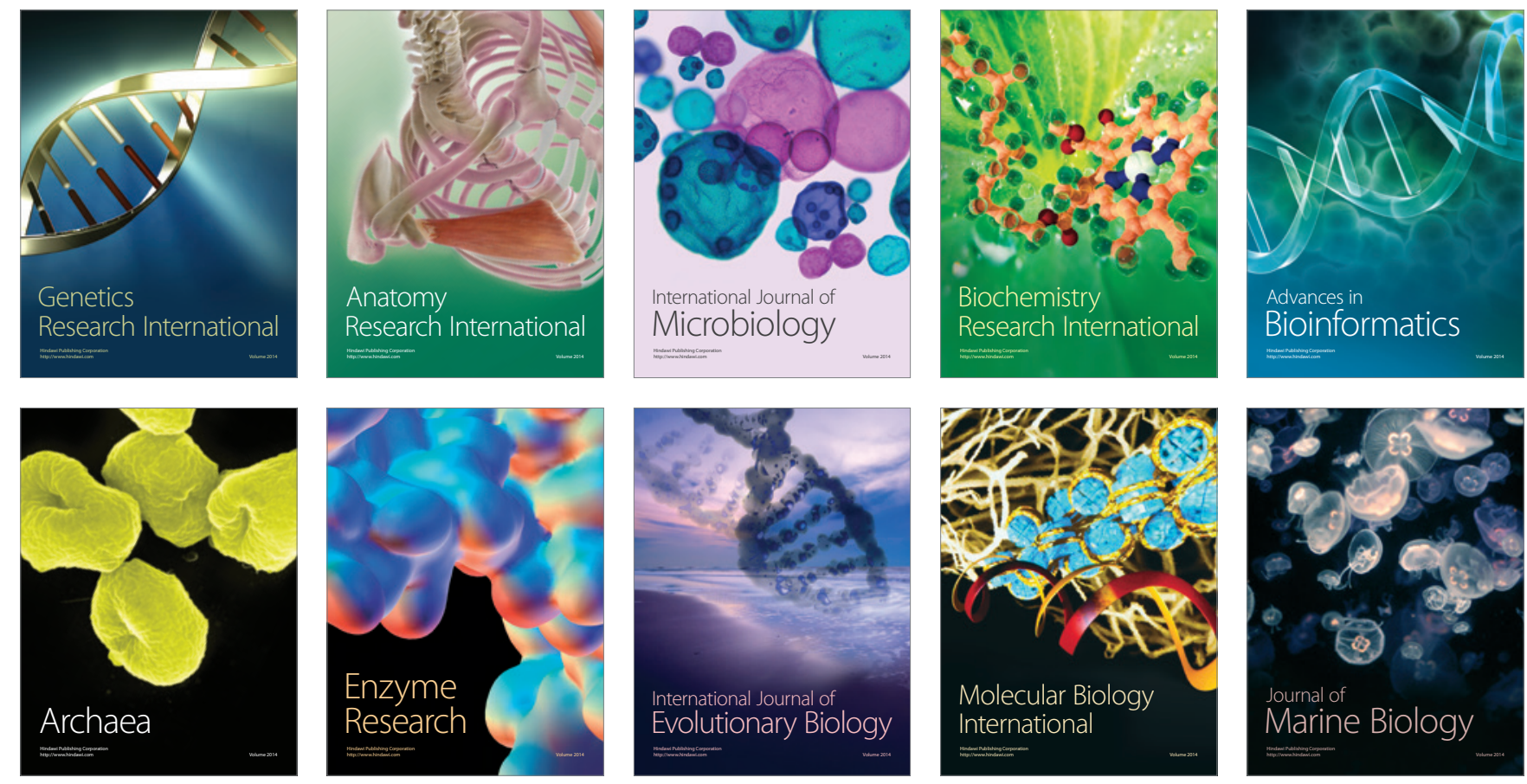